\title{
Studies of critical heat fluxes in small diameter channels ${ }^{*}$
}

\author{
Vladimir I. Belozerov ${ }^{1}$ \\ 1 Obninsk Institute for Nuclear Power Engineering, NRNU MEPhI, 1 Studgorodok, 249040 Obninsk, Kaluga Reg., Russia \\ Corresponding author: Vladimir I. Belozerov (v.i.belozerov@iate.obninsk.ru)
}

Academic editor: Georgy Tikhomirov • Received 2 February 2021 Accepted 2 August 2021 • Published 17 December 2021

Citation: Belozerov VI (2021) Studies of critical heat fluxes in small diameter channels. Nuclear Energy and Technology 7(4): 341-348. https://doi.org/10.3897/nucet.7.78624

\begin{abstract}
The paper presents the results of experimental studies of critical heat flows in vertical small diameter channels, when the coolant moves from bottom to top, which were carried out in the Obninsk branch of MEPhI in the 1970s of the last century but have not become widespread due to the lack of demand for their practical use. Nowadays, the interest in such works is manifested, first of all, in the development of compact plants and devices, particularly in nuclear power engineering.

As a coolant, water, Freon-12 and 96\% ethyl alcohol were used. High velocities of underheated liquid at high heat fluxes on the channel wall lead to the so-called "fast crisis" of heat transfer. In this case, the magnitude of the heat flux depends mainly on the parameters of the coolant flow in the wall zone rather than the flow core. The "slow crisis" is mainly observed at high vapor concentrations, relatively low mass flow rates and in an annular-dispersed flow. The value of the critical heat flow in this case depends mainly on the flow parameters in the core, which are probably close to the average coolant flow parameters. The conditions in the near-wall region are also largely determined by the flow in the core. High heat transfer coefficients in a flow moving at high speed usually result in a much smaller and slower rise in the wall temperature. Sometimes a DNB heat flux can occur bypassing the boiling process. In the core of a VVERtype reactor operating in its nominal mode, surface boiling is present in a number of fuel rods. Probably, surface boiling will also be present in transportable and small-size nuclear power plants. Therefore, an important task is to conduct relevant research in this area.
\end{abstract}

\section{Keywords}

Critical heat flow, departure from nucleate boiling, boiling margin, highly efficient cooling technology

\section{Problems of critical heat flux studies}

When developing small-sized technical devices, designers and researchers face problems associated with generation of heat (Tolubinsky 1980, Yagov and Luzin 1985a, Inasaka et al. 1989, Kirillov 1996, Tong et al. 1997, Dedov et al. 2002, Kandlikar 2002, Zakharov 2003, Malakhovsky 2008, Dedov 2009, Belyaev 2018). Specifically, superheating of the liquid's near-wall layer may occur during cooling the core of a transport reactor, radar systems, electro-

nic generator lamps, and all kinds of electronic devices. The surface temperature of the heat-generating wall, even in conditions of cooling with a subcooled liquid, becomes much higher than the saturation temperature, but despite this, there will be no boiling. The contributors to this are high velocity of the flow, its hydrodynamic stability, the flow core subcooling, and the minimum amount of gas dissolved in the liquid. Operation of these devices, in which thermal energy dissipation can reach up to $1 \times 10^{4}$ $\mathrm{kW} / \mathrm{m}^{2}$, requires heat to be removed. To meet the complex

* Russian text published: Izvestiya vuzov. Yadernaya Energetika (ISSN 0204-3327), 2021, n. 3, pp. 44-57. 
requirements regarding dissipation of heat, it becomes important to develop a new cooling technology for heat fluxes with enormous values.

Highly efficient cooling technology based on boiling in small-diameter channels is one of the issues to be addressed in a heat transport investigation. The advantages of this cooling technology are significant, including small pressure losses, high heat transfer, temperature uniformity, the possibility of cooling at hot spots, etc.

Heat transfer in two-phase gas-liquid and boiling flows in small-diameter channels differs significantly from heat transfer in large-diameter channels. The constraints caused by the flow conditions in the channels affect greatly the heat exchange in two-phase flows. The issues under research in this field are the onset of boiling, the boiling liquid flowing process, hydrodynamic instability, pressure drop and heat transfer.

However, little attention is given to critical heat flux issues, despite the fact that the knowledge in this domain is necessary for designing small-sized devices and ensuring the safety of heat removal. In addition, the results of investigating the heat flux in the process of convective boiling can be used to analyze the state of this flux in small-diameter channels and to identify the critical heat flux mechanism. Although the phenomenon of departure from nuclear boiling (DNB) has been known since a long time ago, the evolution mechanism of this process has not yet been fully studied (Yagov and Luzin 1985a, Inasaka et al. 1989, Tong et al. 1997, Dedov et al. 2002, Kandlikar 2002, Zakharov 2003, Malakhovsky 2008, Dedov 2009).

The critical heat flux defines the conditions for heat transport by the boiling flow in small-diameter channels. To build effective heat transfer devices, one needs to understand clearly the mechanism by which a critical heat flux occurs in small-diameter channels and to develop methods to predict the critical heat flux. This paper presents data from experimental and theoretical studies for critical heat fluxes. Both supercooled and saturated boiling flows are considered. High liquid velocities and small diameters lead to high heat transfer rates, this being caused by the turbulence of the flow in the near-wall region. With low pressures, specifically high superheats are possible. Therefore, the growth rate of a vapor bubble during boiling of a liquid in the wall layer turns out to be very high. Such a process can lead to the channel being plugged by vapor and the subsequent reversal of the circulation, which will cause the cooling failure and the channel breakdown with continued generation of heat.

\section{Classification of channels by size}

We shall dwell on the differences in dimensions of smalland large-diameter channels. So far, no general agreement has been reached on this. Kandlikar (Kandlikar 2002) proposed that channels be differentiated depending on the hydraulic diameter value, $d$ : regular channels $(d>3 \mathrm{~mm})$; small-diameter channels ( $3 \mathrm{~mm} \geq d \geq 200 \mu \mathrm{m})$, and microchannels $(200 \mu \mathrm{m}>d \geq 10 \mu \mathrm{m})$.

According to this definition, the difference between small- and large-diameter channels is $3 \mathrm{~mm}$. However, this definition of a small-diameter channel does not take into account various physical criteria fit to be used to this end. In the absence of a well-grounded definition for small and regular channels, the tube interface, a diameter of $3 \mathrm{~mm}$, was taken as the criterion for the channel differentiation, as recommended in (Dedov et al. 2002).

\section{Critical heat flux}

When the boiling flow moves along the heated channel, a sufficiently rapid increase in the channel wall temperature at a particular time and at particular points can cause the heat transfer coefficient to decrease rapidly and the wall temperature at these points to increase sharply. This phenomenon is called critical heat flux. It is also known by other names such as burnout, dryout, departure from nucleate boiling, and boiling crisis. Critical heat flux is one of the important design characteristics for devices, in which heat is removed from the solid surface into the coolant flow. A major decrease in the heat transfer coefficient results from the loss of the liquid contact with the solid surface, on which the flow evaporates or boils, or bubble convective boiling takes place. Depending on the heat flux magnitude, the thermophysical properties and the operating conditions, the loss of the coolant contact with the surface can lead to the surface superheating, burnout, or some other form of the catastrophic system failure. In design, it is obviously necessary to determine the limit corresponding to the critical heat flux.

Depending on whether the bulk of the liquid at the channel outlet is supercooled or saturated with vapor, the critical heat flux of the liquid is classified as supercooled and saturated, respectively. These two types of a critical heat flux are associated with different mechanisms of its occurrence. A saturated critical heat flux occurs in a situation when the temperature of the liquid at the channel inlet is higher than the temperature of the vapor-saturated flow. The conditions that usually lead to a saturated critical heat flux include low mass flow rate, low supercooling at the inlet, and a high channel length-to-diameter ratio. The drying of the liquid film near the channel outlet is normally looked upon as a mechanism for triggering a saturated critical heat flux (Tolubinsky 1980, Yagov and Luzin 1985a, Tong et al. 1997, Zakharov 2003).

A supercooled critical heat flux occurs in a situation when the liquid at the channel outlet is supercooled. The supercooled critical heat flux is caused by a high mass flow rate, high supercooling at the channel inlet, as well as a small channel length-to-diameter ratio. At the channel outlet, the flow remains mainly in a liquid state with a large number of very small vapor bubbles at the hot wall. Several theories have been proposed to explain the mechanism of triggering a supercooled critical heat flux. 
Departure from nucleate boiling (DNB) in small-diameter channels was investigated in works by V.V. Yagova (Yagov and Luzin 1985a), V.I. Tolubinsky (Tolubinsky 1980), P.L. Kirillov (Kirillov 1996), A.P. Ornadsky and A.M. Kichigina (Ornadsky and Kichigin 1961), V.P. Skripov (Skripov 1972), D.A. Labuntsov (Labuntsov 2000), and others. The purpose of the studies was to obtain mainly quantitative dependences of the limiting heat fluxes resulting in a deteriorated heat exchange. In most of the works, the occurrence of DNB was explained from the point of view of a "hydrodynamic hypothesis".

Despite a large number of works, e.g. (Martinelli 1938, Ornadsky and Kichigin 1961, Rassokhin et al. 1963, Goldstein 1966, Skripov 1972, Tolubinsky 1980, Yagov and Luzin 1985, Kirillov 1996, Tong et al. 1997, Labuntsov 2000, Petukhov et al. 2003, Zakharov 2003, Volynov 2013, Kirillov and Terentyeva 2017), the process of heat transfer from the channel wall to the subcooled liquid flow is not fully understood. Reliable solutions exist only for the laminar flow mode. Turbulent mode, due to the complexity of the turbulent structure, does not yet lend itself to a complete theoretical justification. Therefore, most of the achievements have been the result of using experimental data and semi-empirical theories based on it. One of the first ideas used to develop a semi-empirical theory was the reasoning by $\mathrm{O}$. Reynolds that heat and momentum transports in conditions of a developed turbulence were similar. For the time since the work by $\mathrm{O}$. Reynolds, in which the similarity of "relative molar motion" and thermal motion of molecules was first pointed out, statistical hydromechanics subsequently has formed as a field of research. The low efficiency of this approach has led to the need for developing phenomenological approaches, which represent a combination of certain theoretical concepts and experimental data. To date, the most popular among such approaches has been the semi-empirical theory by L. Prandtl proposed by him in 1926 (Volynov 2013, Kirillov and Terentyeva 2017), which considers the process of the friction force momentum transport between the layers of a turbulent flow. The Reynolds analogy was further developed in works by Karman (Goldstein 1966) and Martinelli (Martinelli 1938). Achievements in the field of semi-empirical theories of heat transfer are also disclosed in works by teams led by B.S. Petukhov (Petukhov et al. 2003), N.I. Buleyev (Buleyev 1989), S.S. Kutateladze (Kutateladze 1979), and others.

The problem of liquid superheats was discussed by V.P. Skripov from the standpoint of the frequency of the viable vapor bubble nuclei occurrence in liquid. Under his leadership, numerous experiments were carried out to determine the superheating limits for water, N-pentane, $\mathrm{N}$-hexane, ether and other liquids. These studies helped describing more fully the thermodynamic state of the liquid-vapor system, and find out the limits for the metastable state regions. According to V.P. Skripov, a thermodynamic crisis is defined by the limit of thermodynamically possible liquid superheats. The thermodynamic approach places emphasis on the wall temperature, $t_{\text {wall }}$, as the key determining parameter with a given external pressure. There are several opinions regarding the key mechanism of heat transfer during boiling from the heating surface. One of these is based on an assumption that the defining mechanism of heat transfer during bubble boiling is unsteady thermal conductivity and the replacement of the superheated layer by the cold liquid as the bubble separates. This model takes into account the properties of the heat exchange surface and allows different forms of the critical heat flux dependence on superheats.

Mudawar and Bowers experimentally investigated an ultra-high critical heat flux in a supercooled boiling water flow (Mudawar and Bowers 1999). They looked into the effect of the liquid parameters and the tube geometry on the critical heat flux (diameter of 0.406 to $2.54 \mathrm{~mm}$ with a length-to-diameter ratio of 2.4 to 34.1 , mass flow of 5000 to $134000 \mathrm{~kg} / \mathrm{m}^{2} \mathrm{~s}$, tube outlet pressure of 2.5 to 172.4 bar). It was found that the critical heat flux grew with the increase in the mass flow rate and the degree of supercooling and with the reduction in the tube diameter and the length-to-diameter ratio. With a constant temperature at the tube inlet, the critical heat flux increases as the pressure rises to $30 \mathrm{bar}$, remains then invariable in a range between 30 and 150 bar, and decreases further when the critical pressure is approached. The critical heat flux occurrence is accompanied by the tube wall burning out in the exit area where it fails. The effect of the tube material on the critical heat flux value is not great.

Another standpoint assumes that the mechanism of heat transfer during nucleate boiling is defined by the mass transport inside the bubble. Such transport was discussed in (Celata et al. 1994) and consists in the thin liquid film evaporating between the vapor bubble and the heated surface with simultaneous condensation in the upper part of the bubbles. An experimental test was undertaken in (Chun et al. 1999) to investigate the mechanism of heat transfer as part of studying the latent heat transport both during boiling and simulated boiling via gas bubbling. The results of the experiments have made it possible to conclude that the turbulization of the boundary layer by the gas bubbles does not provide for such high heat transfer coefficients as take place during boiling (Vasilyev 1972, Chun et al. 1999).

Experimental studies undertaken with round tubes of $1 \mathrm{Kh} 18 \mathrm{~N} 10 \mathrm{~T}$ or $1 \mathrm{Kh} 18 \mathrm{~N} 9 \mathrm{~T}$ steel with internal diameters from 0.74 to $3.26 \mathrm{~mm}$ have been considered (Boltenko et al. 1991, Kirillov et al. 2007). The fluid flow rate was in a range of 0.2 to $40 \mathrm{~m} / \mathrm{s}$, and the pressure ranges at the channel outlet were from 0.29 to 1 bar. Water, Freon-12 and $96 \%$ ethyl $\%$ alcohol were used as coolants. The flow in the circuit was created by the liquid being forced over by pressure from the pressure tank into the drain tank using compressed nitrogen.

Fig. 1 shows a schematic of the setup. It consists of a pressure tank 1, high-pressure nitrogen cylinders 2 , a gas purification filter 3 , a coolant purification filter 4 , a flow meter 5, a fluid (coolant) heater 6, a working section 7 , power measuring devices 8 , and a bypass line 9 . The 


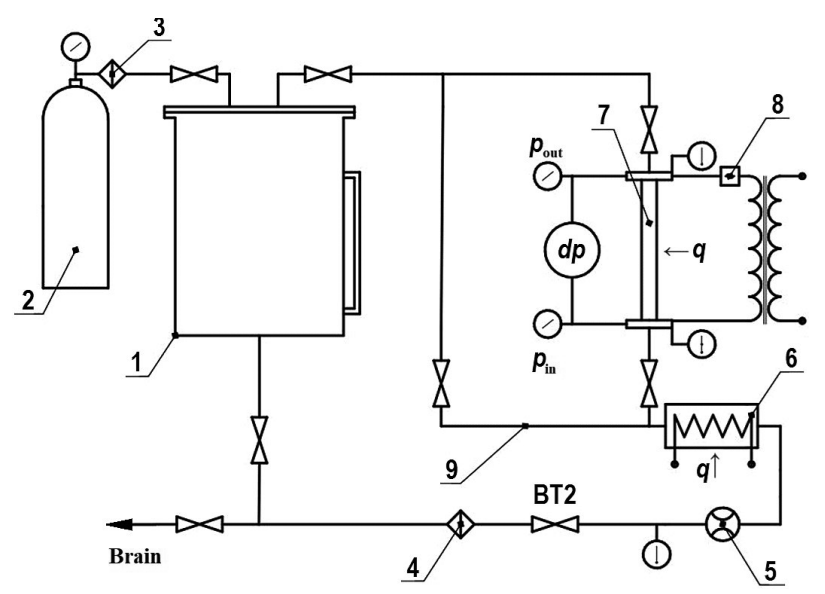

Figure 1. Schematic of the setup.

working section is between two chambers: the inlet (lower) one and the outlet (upper) one.

To supply power to the test channel, copper bus lines were attached on the working section using copper cones and washers. To compensate for temperature expansions, the lower conductor was made movable and was installed in a stainless steel sleeve on springs. The flow rate was measured volumetrically and using a pressure differential flow meter. Valves were used to control the flow rate. The system's pressure-force valves were used to pump back the liquid after the experiment was over.

The power circuit comprised an AOMKT 100/0.5A low-voltage regulating transformer, an OSU-80 power transformer of up to $100 \mathrm{kVA}$, a control system, and power and temperature measuring devices.

The temperature of the liquid at the working section inlet and outlet was measured with the use of pre-calibrated copper-constantan and chromel-copel thermocouples. The wall temperature was measured using 12 to 32 pre-calibrated chromel-alumel thermocouples with the thermoelectrode diameters of 0.1 to $0.2 \mathrm{~mm}$, which were either contact welded to the tube's outer surface or fastened with a thin layer of the BF- 88 glue. Depending on the channel's cross-section diameter, two to four thermocouples were installed along the channel perimeter. The heat outflow through the thermoelectrodes was estimated and the temperature of the heat-transfer surface along the channel length was updated.

The experimental study methodology was as follows. Prior to the experiments, the coolant was heated for a long time to reach the saturation temperature at a pressure of up to 15 bar. A pressure of about 20 to 25 bar was then created in the pressure tank. Nitrogen was used to remove air from the system, and then valves were used to make the coolant flow constant, the measuring devices were switched on and, 15 to 20 minutes after, DC power was delivered to the working section. A system of valves was used to make the liquid flow rate in the channel constant. The thermal power supply was stepwise, with time stops to make sure that no boiling process started.

As high temperature values were reached for the working section wall, a sharp increase in temperature was ob- served near the upper chamber. The thermocouple measuring the liquid temperature at the channel outlet also recorded a sharp growth in temperature. This temperature increase was accompanied by the tube reddening in its upper part and the downward spread of the red glow. A pressure increase was observed in both chambers. If there was no time to reduce the power supplied, the working channel failed, that is, the liquid boiled quite abruptly with high liquid superheats in the wall layer leading to the channel being plugged by vapor, this causing the cooling failure and the channel breakdown with continued generation of heat. With loads close to critical in particular channel areas, there were vapor bubbles appearing on the wall, which were successively carried over into the flow core. The removal of each further bubble was accompanied by its replacement with the vapor-liquid mixture from the flow core. As it contacted the wall, the liquid boiled, and there was an increased density of the vapor bubbles observed in the near-wall region. As they grew on the wall reaching sizes close to the separation diameter, the bubbles merged with each other and with the bubbles brought into the wall layer from the flow. This led to the formation of a vapor conglomerate with a liquid film at its base. The film thickness was defined by the process conditions.

Assuming that all of the heat is used for the bubble growth, we shall get an approximate relation for the heat flux through the bubble ends using the solution of a heat conduction equation subject to two assumptions: there is a heat source with the specific power $q_{v}, \mathrm{~W} / \mathrm{m}^{3}$, acting inside the liquid; and all of the heat is used for the bubble growth. Then the heat balance equation can be written as follows:

$$
2 \rho^{\prime}(\tau) \frac{\pi d^{2}}{4} d \tau=r \rho^{\prime \prime}(\tau) \frac{\pi d^{2}}{4} d h,
$$

where $\rho^{\prime}$ is the density of the heat flux from the boiling liquid; $r$ is the evaporation heat; $\rho^{\prime \prime}$ is the density of dry saturated steam; and $h$ is the bubble height.

The dependence of the critical heat flux was sought in this study as

$$
q \sim w^{n} d^{m} l^{k}
$$

The experiments have shown that the indicators $n=$ $1.2, m=0.8$ and $k=-0.4$ have one common multiplier, so the following can be written

$$
q_{\mathrm{cr}}=f\left(w^{3 / 2} d / l^{1 / 2}\right)
$$

After being processed, the experimental results showed that the data (Fig. 2) was described with an accuracy of $\pm 15 \%$ by the relationship for Freon- 12

$$
q_{c r}=0.454 \cdot 10^{7}\left(\sqrt{w^{3}} \frac{d}{\sqrt{l}}\right)^{0.8}, k W / m^{2}
$$

and for $96 \%$ ethyl alcohol

$$
q_{c r}=0.791 \cdot 10^{7}\left(\sqrt{w^{3}} \frac{d}{\sqrt{l}}\right)^{0.8}, \mathrm{~kW} / \mathrm{m}^{2}
$$




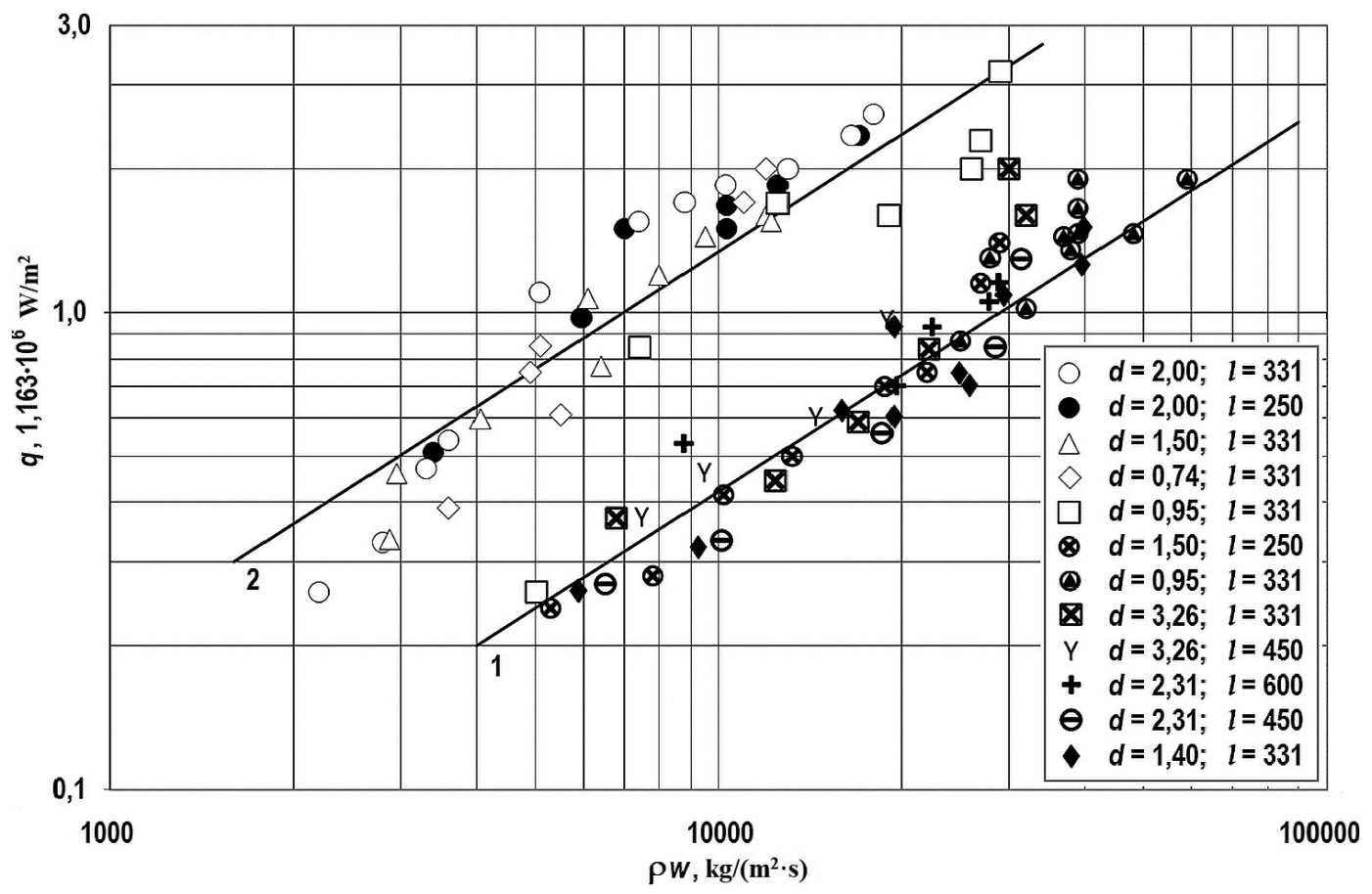

Figure 2. Dependencies $q_{\mathrm{cr}}=f(\rho w): 1-$ Freon-12;2-96\% ethyl alcohol.

The specific heat flux was determined by dividing the electric power supplied to the experimental section by its inner surface. The maximum relative error in determining the heat flux density did not exceed $2 \%$. Since the liquid is heated intensely and its physical parameters change at high heat flux values, the heat-transfer surface temperature $t_{\text {wall }}$, the liquid temperature $t_{\text {liq }}$, the liquid subcooling $\Delta t_{\text {sub }}$, the temperature difference between the wall and the liquid, $\Delta t$, and the heat transfer coefficient $\alpha$ were determined by the experimental section areas which contained thermocouples. The temperature of the section's inner surface in the given area was found taking into account the temperature drop in the wall using the following formula

$$
\Delta t_{\text {wall }}=\frac{q}{4 \lambda} d_{\text {in }}\left(\frac{2 d_{\text {out }}{ }^{2} \ln \left(d_{\text {out }} / d_{\text {in }}\right)}{d_{\text {out }}{ }^{2}-d_{\text {in }}{ }^{2}}-1\right) .
$$

The heat conduction coefficient for stainless steel the above formula includes was taken from a handbook (Boltenko et al. 1991). The maximum relative error, $\Delta t_{\text {wall }}$, did not exceed $5 \%$.

Fig. 3 presents the results of calculating the diameter as a function of the critical heat flux at the Institute of Physics and Power Engineering (IPPE) in Obninsk, with a flow of Freon-12 in vertical tubes uniformly heated by electric current (Boltenko et al. 1991). Qualitatively similar dependences of the critical heat flux on the tube diameter can be observed in other coolants as well, for example, in water (Fig. 4) (Boltenko et al. 1991). Several areas with a different nature of influence can be identified in both figures: the diameter increase in the region with low void fractions leads to an increased critical heat flux. A larger tube diameter probably leads to improved mass exchange between the flow core and the two- phase near-wall layer, i.e. the outflow of bubbles from the wall increases, which delays the onset of the departure from nuclear boiling and increases the critical heat flux density.

Fig. 5 presents the experimental data from (Poletavkin and Shapkin 1958) which shows that the experimental points are perfectly well described by the dependence for convective heat transfer proposed by M.A. Mikheyev (Petukhov et al. 2003). For the transitional boiling zone, the heat transfer coefficient is usually calculated approximately from the depen-

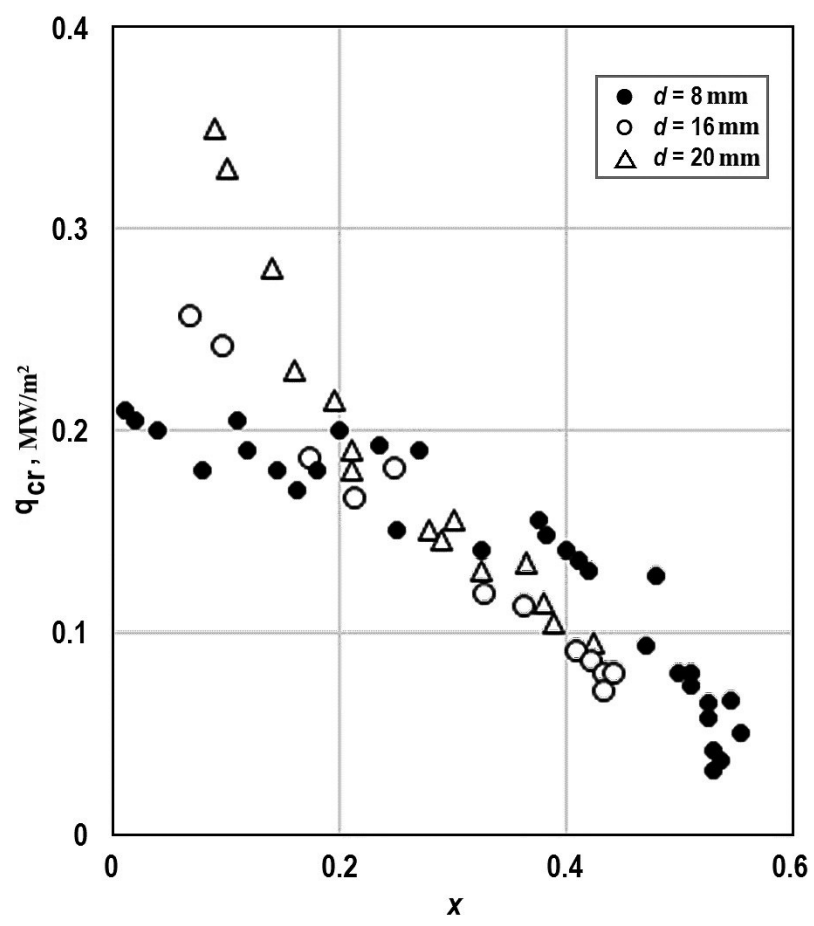

Figure 3. Critical heat flux as a function of mass void fraction (Freon-12, $p=14.7 \mathrm{MPa}, \rho w=4000 \mathrm{~kg} /\left(\mathrm{m}^{2} \cdot \mathrm{s}\right)$ ). 


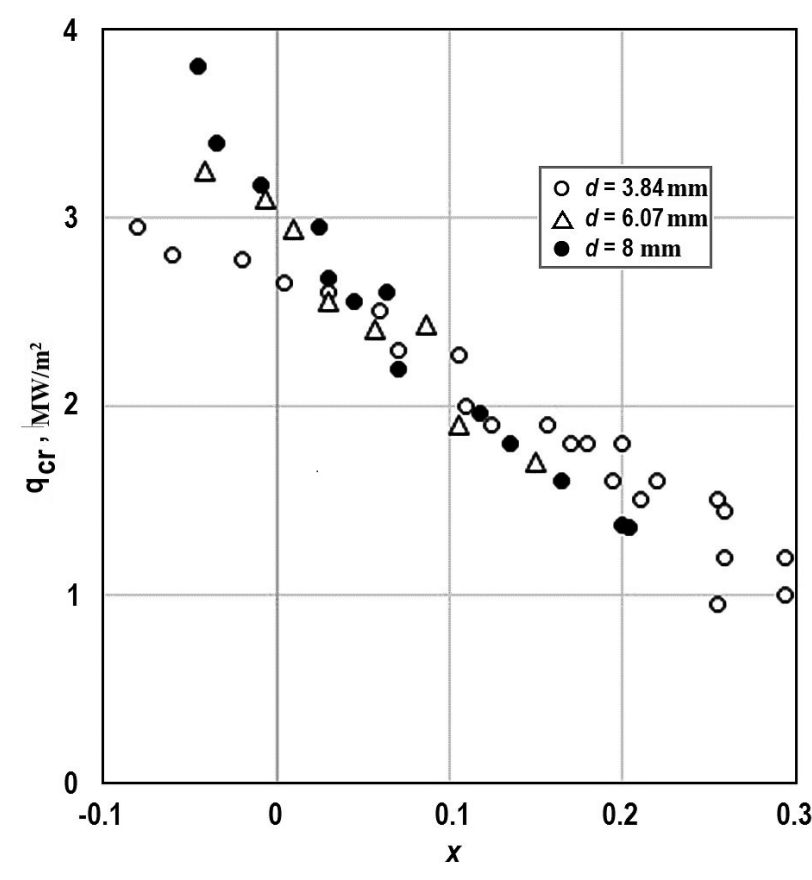

Figure 4. Critical heat flux as a function of mass void fraction (water, $p=14.7 \mathrm{MPa}, \rho w=4000 \mathrm{~kg} /\left(\mathrm{m}^{2} \cdot \mathrm{s}\right)$ ).

dence for convective heat transfer. And the largest deviations from the approximation line are observed when the heat flux values are relatively small and the subcooling is great. The figure compares the intensity of heat transfer during boiling with the heat transfer during convective heat exchange for a single-phase liquid. During boiling, the heat transfer with the same rate is much higher than during forced convection.

Both during surface boiling and conventional convective heat exchange, the principal thermal resistance is a very thin layer of liquid called the boundary layer. The boiling process turbulizes heavily the boundary layer of the liquid and contributes to an increased intensity of heat exchange between the liquid and the wall. Heat transfer during boiling also depends on pressure. Experimental data on heat transfer during surface boiling of water is proportional to $p^{0.35}$ in the minor subcooling region and to $p^{0.25}$ in the major subcooling region.

Fig. 5 confirms that the data from all experiments with surface boiling and convective heat exchange fits quite well into one common straight line, which coincides with that of convective heat exchange since heat transfer during convective heat exchange was taken as standard for determining heat transfer during surface boiling (Poletavkin and Shapkin 1958).

Fig. 6 shows experimental data in (Poletavkin and Shapkin 1958, Rassokhin et al. 1963, Remizov 2006), which, as shown in (Remizov 2006), are described well by the expression

$$
f\left(\Delta t_{\mathrm{i}}\right)=\frac{w^{0,4+0,007 w^{2}}}{q^{0,7} p^{0,5}} .
$$

There is almost no difference between surface boiling and developed boiling with $\Delta t_{\text {sub }} \leq 15{ }^{\circ} \mathrm{C}$, so there is a major scatter of experimental data observed in the plots in this region (Remizov 2006).

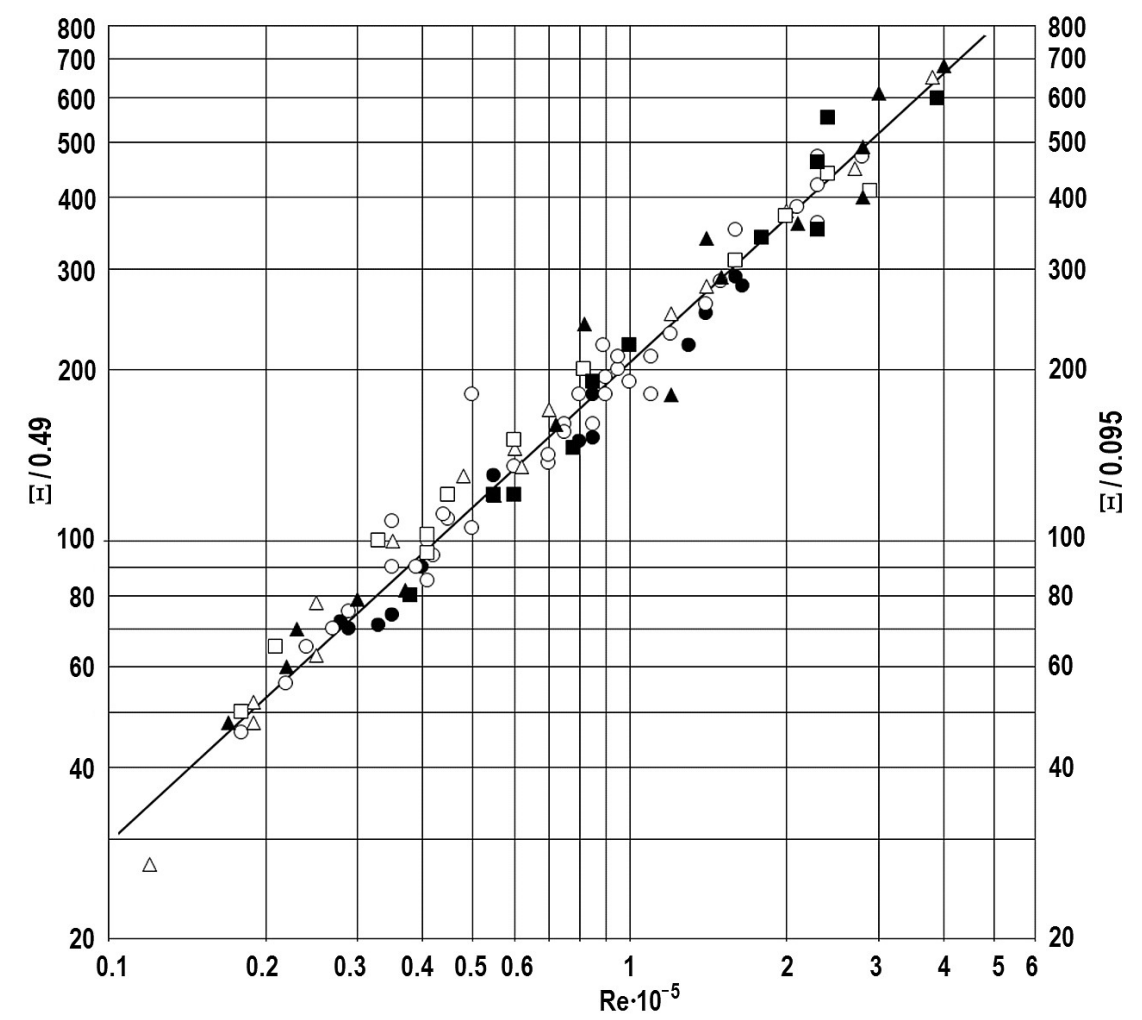

Figure 5. Heat transfer during surface boiling of water. The left ordinate axis $\mathbf{\Xi} / 0.49$ corresponds to major subcooling (light markers). Right axis $\boldsymbol{\Xi} / 0.095$ : subcooling does not affect heat transfer or affects it slightly (black markers). $\boldsymbol{\Xi}=\mathrm{Nu}_{\text {boil }} \times\left(\operatorname{Re} \times \Delta t_{\text {sub }}\right)^{0.63 /}$ $\left[\operatorname{Pr}^{0.43}\left(\operatorname{Pr}_{\text {liq }} / \operatorname{Pr}_{\text {wall }}\right)^{0.25} q^{0.7} p^{0.25}\right]$. Pressure markers: circle -7 ATA; triangle - 16 ATA; square -41 ATA. 


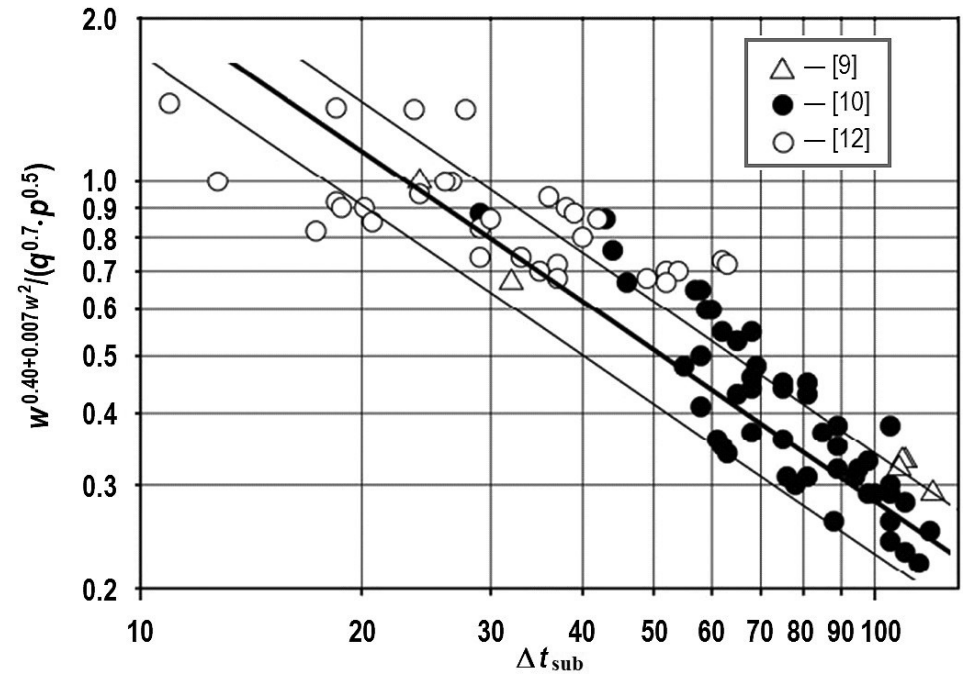

Figure 6. Data on the onset of surface boiling during forced movement of subcooled water in the channel.

\section{Conclusions}

Studies with small-diameter vertical channels with an upward moving coolant flow have been considered. The experiments were carried out with water, Freon-12 and $96 \%$ ethyl alcohol.

It has been shown that the attempts undertaken by many researchers to compare the results of their experiments with the data obtained based on the available formulas were not at all times successful. Formulas obtained on the basis of one's own data are often inapplicable to data from other researchers. The conjugate effects of heat transfer are often ignored; no influence of flow instabili- ty was investigated in some experiments. The effects of the axial conductivity through the tube walls or through blocks can change greatly the conditions for the critical heat flux to occur. The flow fluctuations affect adversely the critical heat flux conditions. As a rule, the flow distribution in parallel channels is not uniform. Since the conditions for the critical heat flux existence depend on the coolant velocity (and the exact velocity in the channels is not known), the results of experiments with parallel channels cannot be regarded reliable. Currently, the information on the critical heat flux in small-diameter channels is insufficient to predict the boiling crisis, i.e., there is no accurate and proven model to predict the crisis in small-diameter channels.

\section{References}

- Belyaev AV (2018) An Experimental Study of Hydrodynamics and Heat Exchange in Small Diameter Channels at High Reduced Pressures. Cand. Sci. (Engineering) Diss. Abstr. National Research University MEI Publ., Moscow, 20 pp. [in Russian]

- Boltenko EA, Pometko RS, Katan IB, Zyatnina OA (1991) Influence of the tube diameter on the critical heat flux. Proc. of the Intern. Symposium "Thermophysics-90". Obninsk. FEI Publ., 2: 400-403. [in Russian]

- Buleyev NI (1989) Spatial Model of Turbulent Exchange. Nauka Publ., Moscow, 343 pp. [in Russian]

- Celata GP, Cumo M, Mariani A (1994) Assessment of correlations and models for the prediction of CHF in water subcooled flow boiling. International Journal of Heat and Mass Transfer 37: 2605-2640. https://doi.org/10.1016/0017-9310(94)90096-5

- Chun T, Baek W, Chang SH (1999) A superheated liquid layer depletion model for subcooled and low quality critical heat flux. Proc. of the $7^{\text {th }}$ Int. Conf. on Nuclear Engineering, Tokyo, ICONE-7501: 1-2.

- Dedov AV (2009) Peculiarities of boiling in a subcooled flow. Teploenergetika 8: 62-69. https://doi.org/10.1134/S0040601509080126 [in Russian]

- Dedov AV, Komov AT, Varava AN, Yagov VV (2002) Boiling heat transfer in swirl flow of subcooled water. Proc. of the $12^{\text {th }}$ International Heat Transfer Conference, Grenoble, France, 731-736. https:// doi.org/10.1615/IHTC12.1610

- Goldstein S (1966) Theodore von Karman, 1881-1963. Biographical Memoirs of Fellows of the Royal Society 12: 335-365. https://doi. org/10.1098/rsbm.1966.0016

- Inasaka F, Nariai H, Shimura T (1989) Pressure drops in subcooled flow boiling in narrow tubes. Heat Transfer Japanese Research 18: 70-82.

- Kandlikar SG (2002) Fundamental issues related to flow boiling in minichannels and microchannels. Experimental Thermal and Fluid Science 26: 389-407. https://doi.org/10.1016/S0894-1777(02)00150-4

- Kirillov PL (1996) Departure from nucleate boiling in channels. Atomnaya Energiya 80(5): 370-379. [in Russian]

- Kirillov PL, Terentyeva MI (2017) Prandtl Turbulent Number (History and Modernity). Preprint GNTs RF-FEI 3271. Obninsk. GNTs RF-FEI Publ., 56 pp. [in Russian]

- Kirillov PL, Terentyeva MI, Deniskina NB (2007) Thermophysical Properties of Nuclear Technology Materials. IzdAt Publ., Moscow, 200 pp. [in Russian] 
- Kutateladze SS (1979) Fundamentals of the Heat Transfer Theory. Atomizdat Publ., Moscow, 416 pp. [in Russian]

- Labuntsov DA (2000) Vapor content of a two-phase adiabatic flow in vertical channels. In: Physical Fundamentals of Power Engineering. Ed. by T.M. Muratov. MEI Publ., Moscow, 204-212. [in Russian]

- Malakhovsky SA (2008) Heat Exchange during Boiling in the Forced Current Conditions of a Swirling Flow in Small Diameter Channels. Cand. Sci. (Engineering) Diss. Abstr. GOU VPO MEI (Tekhnichesky Universitet) Publ., Moscow, 20 pp. [in Russian]

- Martinelli E (1938) Alkuni teoremi integrali per le funzioni analitiche di piuvariabili complesse. JFM64.0322.04, Zbl 0022.24002, 9(7): 269-283. [in Italian]

- Mudawar I, Bowers MB (1999) Ultra-high heat UX (CHF) for subcooled water OW boiling-1: CHF data and parametric effects for small diameter tubes. International Journal of Heat and Mass Transfer 42: 1405-1428. https://doi.org/10.1016/S0017-9310(98)00241-5

- Ornadsky AP, Kichigin AM (1961) A study into the dependence of critical heat load on mass velocity, subcooling and pressure. Teploenergetika 2: 75-79. [in Russian]

- Petukhov BS, Genin LG, Kovalev SA, Solovyev SL (2003) Heat Exchange in Nuclear Power Plants. MEI Publ., Moscow, 548 pp. [in Russian]

- Poletavkin PG, Shapkin NA (1958) Heat transfer during surface boiling of water. Teploenergetika 5: 72-76. [in Russian]

- Rassokhin NG, Ma Tsang-Wen, Melnikov VN (1963) Heat transfer during surface boiling in narrow annular channels. Teploenergetika 5: 83-85. [in Russian]

- Remizov OV (2006) On the onset of surface boiling. Proc. of the $4^{\text {th }}$ Russian Regional Conference on Heat Exchange (RNKT-4), Oct
23-27, Vol. 4. Boiling, Departures from Nucleate Boiling, Post Dryout. MEI Publ., Moscow, 194-196. http://rnkt.ru/2006/tom-4/page194/ [accessed Jan. 31, 2021] [in Russian]

- Skripov VP (1972) Metastable Liquid. Nauka Publ., Moscow, 312 pp. [in Russian]

- Tolubinsky VI (1980) Heat Exchange during Boiling. Naukova Dumka Publ., Kiev, 315 pp. [in Russian]

- Tong W, Bergles AE, Jensen MK (1997) Pressure drop with highly subcooled flow boiling in small-diameter tubes. Experimental Thermal and Fluid Science 15(3): 202-212. https://doi.org/10.1016/ S0894-1777(97)00018-6

- Vasilyev AN (1972) Departure from Nucleate Boiling Associated with Abrupt Liquid Boiling in Channels of Small Diameter. Cand. Sci. (Engineering) Diss. Abstr. Institut Tekhnicheskoy Teplofiziki Publ., Kiev, 31 pp. [in Russian]

- Volynov MA (2013) Real turbulence and possibilities for modification of L. Prandtl's semi-emperical theory. Fundamentalnye Issledovaniya 10(part 8): 1676-1688. [in Russian]

- Yagov VV, Luzin VA (1985) An approximate physical model of the departure from nucleate boiling in a forced flow of a saturated liquid. Teploenergetika 3: 2-5. [in Russian]

- Yagov VV, Luzin VA (1985a) Boiling crisis in the forced motion conditions of a subcooled liquid. Teploenergetika 10: 52-54. [in Russian]

- Zakharov SV (2003) A model of the departure from nucleate boiling during bubble boiling of liquids in channels with high reduced pressures. Cand. Sci. (Engineering) Diss. Abstr. Natsionalny Issledovatelsky Universitet MEI Publ., Moscow, 20 pp. [in Russian] 